\title{
Stressors and Coping Strategies of the Saudi Nursing Students in the Clinical Training: A Cross-Sectional Study
}

\author{
Salman H. Alsaqri \\ Medical Surgical Department, College of Nursing, University of Hail, Hail, Saudi Arabia \\ Correspondence should be addressed to Salman H. Alsaqri; slmn44@gmail.com
}

Received 6 April 2017; Accepted 24 May 2017; Published 14 June 2017

Academic Editor: Gwo-Jen Hwang

Copyright (C) 2017 Salman H. Alsaqri. This is an open access article distributed under the Creative Commons Attribution License, which permits unrestricted use, distribution, and reproduction in any medium, provided the original work is properly cited.

\begin{abstract}
Nursing students often encounter high levels of stress through clinical practice that may cause psychological or emotional problems during their professional life eventually affecting the quality of patient care they provide. The aims of the current study were to identify the level and types of stress perceived by nursing students in their clinical practice and to identify the coping strategies that students used to relieve their stress. A descriptive, cross-sectional design was used in this study. A total of 200 students who were enrolled in the nursing program were taken as study respondents. Research data were collected using the Perceived Stress Scale (PSS) and the Coping Behavior Inventory (CBI). Data was analyzed using one-way ANOVA test, Pearson's test, and independent sample $t$-test on SPSS version 22. Findings indicated that nursing students experienced a high level of stress. The most common coping strategy utilized by the students was problem solving, while avoidance was the least frequently used one. Saudi nursing students experienced stress levels above the mean in clinical training. The most common stressors were related to assignments and workload. The study recommends that clinical curriculum requirements and the workload of nursing students should be reviewed.
\end{abstract}

\section{Introduction}

The nursing program has the desired end of producing skilled and qualified nurses who are capable of utilizing their knowledge and skills in the practice of the profession. Therefore, student nurses' clinical training should be appropriately designed for them to develop cognitive, affective, and psychomotor skills that are essential for ascending the nursing career path [1]. Most nursing curricula allocate more than half of the nursing students time for clinical exposure using advanced technical instrumentation and perform nursing skills that may cause severe impairment to their patients, therefore increasing their worry of creating errors. Therefore, they view the clinical area as a very stressful place [2]. Learning challenges of the students in clinical practice may cause stress which may directly or indirectly hinder their performance [3]. Pryjmachuk and Richards [4] indicated that stress during students training is similar to that experienced by registered nurses. Moreover, stress affects almost each profession. However, levels of stress are higher, and there are a greater number of sources of stress among nursing professionals with negative consequences for their health [5].
1.1. Bachelor of Science in Nursing in Saudi Arabia. Saudi Arabia has undergone rapid nursing education changes in recent years with the shift from associate degree education and diploma nursing to the current four-year baccalaureate degree education [6]. The organization of the nursing curriculum is affected by the Ministry of Education and nursing education program requirements [7]. Nursing program requirements contain all subjects related to preparing students for the licensed professional nurse [7]. The last year of the program is an internship period in clinical practice, providing the students with the chance to combine their skills and knowledge. The nursing program is covered over five years which are allocated to lectures, laboratory work, and clinical practice that all delivered using English as a medium of instruction [7]. More specifically, the nursing program at the University of Hail is designed to provide sophomore nursing students fundamental nursing skills in laboratories prior to clinical exposure on their junior and senior year. It includes seventy-two (72) actual hours of clinical exposure supervised and assessed by clinical instructors. Each clinical course is concurrent with a theoretical course. 
Few investigations have been made in the Kingdom of Saudi Arabia related to stress levels among nursing students, sources of stress, and their utilized coping strategies [8, 9]. In particular, At Hail University, College of Nursing, no research studies were conducted in this respect, so an in-depth research is needed to clarify the magnitude of the problem and to emphasize whether these stressors are mostly related to daily hassles, major live events, or academic and teaching style problems. Therefore, it is expected that conducting this study would provide a better insight about the stress perceived and stressors experienced by our nursing students in order to prevent the unwanted effects incurred in the current state of healthcare delivery in Saudi Arabia. This, in turn, would help nursing teachers and clinical instructors to develop effective teaching and learning strategies in clinical settings that could reduce levels of stress and employ adaptive coping behaviors to deal with it [10].

The aims of this study were to identify the level and types of stress perceived by nursing students in University of Hail in their clinical practice, the coping strategies that students used to relieve their stress, and differences of students' characteristics with perceived stress and coping strategies.

\section{Review of Literature}

Using different databases including CINAHL, MEDLINE, and PubMed, a review of the literature was conducted. The inclusion criteria were readily available studies (quantitative and qualitative). The search was limited to English-language journals using the following keywords: nursing students, stress, coping, nursing education, clinical, and practice. In addition, by examining related references in the identified studies, the researchers conducted a secondary literature search, to find the relevant information and get a clear picture about the topic.

Stress is a complex event that happens in the interaction between individuals and their inner and outer environments; such reciprocal interaction can cause physical, mental, emotional, and behavioral changes [11]. Studies indicated that nursing students have higher perceived stress levels when compared to other students in other professional programs [12-14].

Studies showed that there are two main sources of stress among nursing students: academic and clinical stressors, with the latter being perceived more extremely by nursing students [15]. Stressors related to academia include assignments and workloads [14, 16, 17] and examinations [17]. Clinical sources of stress include fear of the unknown [17], engaging in various clinical activities [10], taking care of patients [18], and lack of professional knowledge or nursing skills [16].

In terms of academic achievements, stress experience by nursing students may provide both desirable and undesirable outcomes $[19,20]$. High levels of stress may not only impact academic achievements, but also cause physical impairments like high blood pressure, cardiac disease, gastrointestinal upset, and immunodeficiency disorders [21]. There is evidence implying that stress during clinical practice may lead to psychological impairments such as fear, anxiety, worry, anger, guilt, grief, or depression that subsequently affects the quality of patient care [22]. However, stress is considered helpful by nursing students in decreased levels as it increases excitement and motivation [23].

Coping strategies available to students in the clinical area can manage their stress levels. Useful coping strategies assist students in achieving improved marks that reduce their stress. Numerous studies identified the problem-solving approach as the most commonly utilized coping strategy among nursing students while the avoidance approach was their least utilized coping strategy $[14,16,18]$.

In general, students experience moderate to high levels of stress from various stressors (caring of patients, assignments and workloads, negative interactions with staff and faculty, lack of clinical competence, and taking of examinations) during nursing education. The most commonly used strategy to deal with and cope with stress was the problem-solving approach, an approach considered the most appropriate way of dealing with stress.

\section{Methods}

3.1. Design. The study was descriptive in nature. More specifically, it employed a cross-sectional design in the determination of nursing students' stress levels and its sources. A descriptive design is suitable for use in this study to describe the phenomenon of stress as it currently exists without manipulation [24].

3.2. Sample and Setting. The study took place in the University of Hail, Hail City. All junior and senior nursing students were included to minimize sampling error. The total number of nursing students is 200. No sampling procedure was performed since the entire population was taken as respondents. Inclusion criteria were being a Saudi nursing student, agreeing to participate in the study, and being actively enrolled in the program. The freshmen and sophomore students were excluded from the study since they have not been exposed to having clinical experience prior to the collection of data. Students who were not present during data collection or who were taking time off the program were also excluded.

The nursing program at Hail University where the students were recruited followed the regulations for Saudi nursing education and was controlled by the Saudi Higher Education Authority. Accordingly, the Bachelor of Nursing Science program consists of 5 years. This 5-year program consists of 1 preparatory year +3 academic years +1 internship training program. Clinical practice starts at the beginning of third year for about 1-2 days (8-16 h) of clinical training per week.

3.3. Ethical Consideration. Ethical approval for this study was granted by the Ethical Review Committee of the University of Hail (H-2016-030). In this study, appropriate measures were considered to protect the participant's rights, such as provision of the details of the study via information sheet coupled by an explanation of the aim of the study. A signed consent form was obtained prior to engaging the participants 
into the study. By signing the consent form, it was understood that the participants agreed to be included in the study.

3.4. Measurements. A self-reported questionnaire in three main parts was used for this study, which is composed of a demographic data sheet, Coping Behavior Inventory (CBI), and a Perceived Stress Scale (PSS). Part one provided nursing students' demographic information that included age, gender, years of study, interest in nursing, course enrolled, and previous nursing experience. In part two, the PSS formulated by Sheu et al. [25] was adopted to identify the nursing students' perceived stressors and levels of stress experience in the clinical setting. It had 29 indicators in six subscales using a five-point Likert-type scale. These six subscales were (1) stress related to patient care (8 indicators), (2) stress related to teachers and nursing staff (6 indicators), (3) stress related to assignments and workloads (5 indicators), (4) stress related to peers and daily life (4 indicators), (5) stress related to lack of professional knowledge and skills (3 indicators), and (6) stress related to the clinical environment ( 3 indicators). The total score ranges from 0 to 116. A lower score means lower degrees of stress while the higher score means higher levels of stress. To determine the level of stress, the following scaling was used: $2.67-4.00$ for high stress, 1.34-2.66 for moderate stress, and $0-1.33$ for low stress [26]. The PSS had a Cronbach's alpha coefficient of $0.86-0.89[2,27]$ and the content validity index was 0.94 [28]. In the current study, Cronbach's alpha for the total scale was 0.87 , indicating adequate internal consistency reliability. This tool provided an opportunity for respondents to expand on responses in the nursing stress scale and include stressors and suggestions relating to the clinical environment. It also yielded information on stress and stressors as perceived by them and providing an opportunity for respondents to suggest ways to prevent or manage stress in clinical environment.

The Coping Behavior Inventory (CBI) was formulated by Sheu et al. [26] to identify coping strategies utilized by nursing students in practice courses. It had 19 indicators in four subscales: (1) avoidance behaviors (6 indicators); (2) problem-solving behaviors (6 indicators); (3) optimistic coping behaviors ( 4 indicators); and (4) transference behaviors ( 3 indicators). Each indicator was measured through a five-point Likert scale from 0 to 4 . The instrument had a Cronbach's alpha coefficient of 0.76 and 0.80 in other investigations $[26,28]$. Higher scores of each factor indicate more frequent use and greater effectiveness of a certain type of coping behavior. In the current study, Cronbach's alpha for the total scale was 0.67 , indicating adequate internal consistency reliability. Permission for using the instruments was obtained by the original authors. Content validity for the PSS and CBI in previous investigations that utilized nursing students was 0.87 and 0.73 , respectively [18]. A pilot study to evaluate the readability and clarity of the instruments was conducted using a convenience sample of 20 nursing students who have characteristics like those of the study participants.

3.5. Data Collection. Data gathering commenced upon obtaining approval from the Ethics Review Committee and with the dean of College of Nursing. It started in September
2016 and was completed in December 2016. The researchers approached students during clinical practice, so that the data collected could prove to be more representative for the perceived stress. The researcher approached the students at the end of their clinical practice and explained the purpose of the study. A cover letter with the details of the study was provided to the students and was fully explained. Accomplished questionnaires were subsequently retrieved by the researchers.

3.6. Data Analysis. Data analysis was facilitated using SPSS version 22 for Windows. Data analysis consisted of both descriptive and inferential analysis. Descriptive statistics were used to analyze the demographic data, stress levels, and common stressors as well as the common coping strategies of students. For inferential statistics, bivariate statistical tests $(t$ test and ANOVA) were used to assess the differences between students' demographics and both types of stress and coping strategies. A $p$ value equal to or less than .05 is considered statistically significant.

\section{Results}

4.1. Demographics Characteristics of the Students. The total number of nursing students who were studying at the college at the time of data collection was 310 students. among them, 210 were doing their clinical training during the time of data collection. Ten accomplished questionnaires were omitted due to missing data, resulting in a total number of 200 participants, equivalent to a response rate of $95 \%$. One-third of the student respondents belonged to the age range less than or equal to 21 ( $n=71,35.5 \%)$. A little more than half $(58 \%)$ of the respondents were females $(n=115)$. More than half of the participants $(n=124,62.0 \%)$ were in their third academic year and were enrolled in the course Advance Adult Care Nursing Practice $(n=58,29 \%)$. Majority of the participants $(83.0 \%$, $n=166)$ signified their interest in the nursing profession while close to a fourth of them obtained previous nursing experience $(24.5 \%, n=49)$ (Table 1$)$.

4.2. Perceived Stress and Types of Stressors by Nursing Students. The mean level of stress perceived by the study respondents was 2.68 ( $\mathrm{SD}=0.63)$. Stress from assignments and workload was the most common type of stressor perceived $(\mathrm{M}=$ $2.89, \mathrm{SD}=0.85)$, while stress due to lack of professional knowledge and skills $(\mathrm{M}=12.70, \mathrm{SD}=0.88)$ and from clinical environment $(\mathrm{M}=1.58, \mathrm{SD}=1.07)$ followed. Worrying about grades $(M=3.03, S D=1.09)$, being unfamiliar with professional nursing skills $(\mathrm{M}=2.92, \mathrm{SD}=1.27)$, and pressure from the nature and quality of clinical practice $(\mathrm{M}=2.90$, $\mathrm{SD}=1.29$ ) were other stress factors identified. However, the lowest levels of stress were from "not knowing how to discuss a patient's illness with teachers or medical and nursing personnel" $(\mathrm{M}=2.20$; $\mathrm{SD}=1.50)$, "unfamiliar with medical history and terms" $(\mathrm{M}=2.34 ; \mathrm{SD}=1.10)$, and "lack of care and guidance from teachers" $(\mathrm{M}=3.39$; $\mathrm{SD}=1.48)$ (Table 2).

4.3. Relationship between Coping Strategies and Stress Levels. Pearson product-moment correlation (Pearson $r$ ) coefficient 
TABLE 1: Students demographic characteristic.

\begin{tabular}{lcc}
\hline Variable & Frequency & Percentage \\
\hline Gender & 85 & \\
Male & 115 & 42.5 \\
Female & & 57.5 \\
Age & 71 & \\
$\leq 21.00$ & 70 & 35.5 \\
$22.00-24.00$ & 59 & 35.0 \\
$25.00+$ & & 29.5 \\
Interest in nursing & 166 & \\
Yes & 34 & 83.0 \\
No & & 17.0 \\
Year of study & 124 & \\
Third year & 76 & 62.0 \\
Fourth year & & 38.0 \\
Course enrolled & 45 & \\
Basic Adult Care Nursing & 58 & 22.5 \\
Advance Adult Care Nursing & 48 & 29.0 \\
Critical Care Nursing & 15 & 24.0 \\
Pediatric Nursing & 34 & 7.5 \\
Mental Health Nursing & & \\
Previous experience in nursing & 151 & \\
No & 49 & \\
Yes & & \\
\hline N = 200 & & \\
\hline & &
\end{tabular}

for a 2-tailed test of significance was used to determine the relationship between the levels of perceived stress and adopted coping strategies by nursing students. The results of this study revealed that there was no statistically significant correlation between levels of stress and coping strategies ( $r=$ $-0.133, n=200$, and $p=.110)$.

4.4. Differences of Nursing Students' Characteristics with Perceived Stress. $t$-tests conducted to assess mean differences in levels of perceived stress indicated no significant differences when study respondents were grouped according to gender and interest in nursing. The one-way ANOVA test to determine mean differences of students in different academic years, students age groups, and courses enrolled with perceived students stress indicated that "students age" was the only demographic variable that was significantly different with perceived students stress $(F=4.1, \mathrm{df}=2$, and $p<.05)$. Further analysis with Tukey post hoc test showed that students in the age group 22-24 years had significantly more stress.

4.5. Coping Strategies Utilized by Nursing Students. The overall mean of coping perceived by the study respondents was $2.65(\mathrm{SD}=0.40)$. Coping behaviors most commonly utilized by the study respondents were "problem solving" $(\mathrm{M}=3.35$; $\mathrm{SD}=0.41)$, followed by "staying optimistic" $(\mathrm{M}=3.01 ; \mathrm{SD}$ $=0.8)$ and "transference" $(\mathrm{M}=2.31 ; \mathrm{SD}=1.28)$. However, avoidance was less frequently utilized by nursing students $(\mathrm{M}=1.90 ; \mathrm{SD}=0.92)$. The most common coping behavior of the students was to "set up objectives to solve problems" $(\mathrm{M}=3.43, \mathrm{SD}=0.50)$, "to make plans, list priorities" and "solve stressful events" $(\mathrm{M}=3.43 ; \mathrm{SD}=0.51)$, "to employ past experience to solve problems" $(\mathrm{M}=3.42$; $\mathrm{SD}=515)$, "to have confidence in performing as well as senior schoolmates" $(\mathrm{M}=3.3 ; \mathrm{SD}=0.49)$, and "to find the meaning of stressful incidents” $(\mathrm{M}=3.32 ; \mathrm{SD}=0.50)$ (Table 3$)$.

\section{Discussion}

Levels of stress among nursing students at the University of Hail are considered above the mean. This result is consistent with other studies $[8,13]$. These findings showed that nursing students as they are newly exposed to a highly technological clinical environment combined with the stress of completing new unfamiliar assignments and procedures could have higher stress. Another point that is certainly value stating is that the multicultural and complex clinical environment certainly had an impact on the students' stress. Other investigations identified clinical sources of stress, such as lack of knowledge and professional ability, lack of familiarity with history and medical terms, heavy workload, being in an unfamiliar situation, and mistakes with patients or handling of technical instruments [15-17]. All these could explain why students exposed to the clinical setting were more prone to experience stress. Training in hospitals overcrowded with patients increases the stress levels among the nursing students. According to the demand-control model of stress in the work environment [29], undesirable stress happens in circumstances with a high level of external demands in combination with a low level of individual control. This is possibly the case in overloaded departments and therefore explains why the students experienced an increased level of stress there. The results of this study indicate that clinical instructors and coordinators who have a vital role in the clinical education should be aware of the fact that students who perform practice in a hospital department (in particular, one which is overloaded with patients) are at specific risk of stress. Such students might need prolonged support during their clinical exposure. On the other hand, stress level was mild among Greek student nurses [27]. Mild stress level can be helpful to the individual's health, particularly when confronted with challenge and responsibility [28].

The current study showed that the most common source of stress faced by nursing students is assignments and workload. This is consistent with the results of other studies $[18,30]$. The 4-year Bachelor of Nursing program in Hail University consists of 135 credit hours, among which 36 credit hours (72 actual hours) are clinical training. In each clinical unit, students are required to submit at least three assignments including a nursing care plan, clinical log, and case study reports. In addition, clinical supervision by academic teachers is required to assess the performance of each student, which might have caused additional stress to students. Considering the current study findings, the researchers suggest that the assignment plan should be revised, as reducing assignments number and the workload for nursing students is essential in order to create a motivating clinical environment, as well as providing a supportive environment prior clinical 
TABLE 2: Stressors perceived by nursing students in clinical training.

\begin{tabular}{|c|c|c|c|c|}
\hline Stress factor & Factor ranking & Item ranking & Mean & $\mathrm{SD}$ \\
\hline Stress from lack of professional knowledge and skills & 2 & - & 2.70 & .89 \\
\hline Unfamiliar with medical history and terms & & 28 & 2.34 & 1.11 \\
\hline Unfamiliar with professional nursing skills & & 2 & 2.92 & 1.27 \\
\hline Unfamiliar with patients' diagnoses and treatments & & 5 & 2.85 & 1.24 \\
\hline Stress from assignments and workload & 1 & & 2.89 & .86 \\
\hline Worry about poor grades & & 1 & 3.03 & 1.09 \\
\hline Pressure from the nature and quality of clinical practice & & 3 & 2.90 & 1.29 \\
\hline Feelings that performance does not meet teachers' expectations & & 7 & 2.80 & 1.31 \\
\hline Feelings that dull and inflexible clinical practice affect family/social life & & 4 & 2.88 & 1.18 \\
\hline Feelings that the demands of clinical practice exceed physical and emotional endurance & & 6 & 2.84 & 1.27 \\
\hline Stress from taking care of patients & 4 & - & 2.68 & .81 \\
\hline Lack of experience and ability in providing nursing care and in making judgment & & 26 & 2.49 & 1.42 \\
\hline Not knowing how to help patients with physio-psycho-social problems & & 8 & 2.78 & 1.29 \\
\hline Unable to reach expectations & & 10 & 2.75 & 1.27 \\
\hline Unable to provide appropriate responses to doctors', teachers', and patients' questions & & 17 & 2.67 & 1.34 \\
\hline Worry about not being trusted or accepted by patients or their families & & 12 & 2.73 & 1.28 \\
\hline Unable to provide patients with good nursing care & & 15 & 2.68 & 1.38 \\
\hline Not knowing how to communicate with patients & & 25 & 2.53 & 1.43 \\
\hline Difficulties in changing from the role of a student to that of a nurse & & 9 & 2.76 & 1.29 \\
\hline Stress from clinical environment & 3 & & 2.68 & 1.07 \\
\hline Feelings of stress in the environment where clinical practice takes place & & 13 & 2.73 & 1.40 \\
\hline Unfamiliarity with ward facilities & & 19 & 2.65 & 1.42 \\
\hline Feelings of stress from rapid changes in a patient's condition & & 18 & 2.67 & 1.33 \\
\hline Stress from teachers and nursing staff & 6 & - & 2.52 & .86 \\
\hline Seeing a discrepancy between theory and practice & & 23 & 2.55 & 1.46 \\
\hline Not knowing how to discuss a patient's illness with teachers or medical and nursing personnel & & 29 & 2.20 & 1.50 \\
\hline Feelings of stress when a teacher's instruction is different from expectations & & 14 & 2.73 & 1.22 \\
\hline Medical personnel lacking empathy and willingness to help & & 11 & 2.75 & 1.12 \\
\hline Feelings that teachers do not evaluate students fairly & & 24 & 2.55 & 1.38 \\
\hline Lack of care and guidance from teachers & & 27 & 2.39 & 1.48 \\
\hline Stress from peers and daily life & 5 & - & 2.63 & .95 \\
\hline Experience of competition from peers in school and clinical practice & & 22 & 2.56 & 1.48 \\
\hline Feelings of pressure from teachers who evaluate students' performance by comparison & & 16 & 2.68 & 1.41 \\
\hline Feelings that clinical practice affects involvement in extracurricular activities & & 20 & 2.65 & 1.29 \\
\hline Inability to get along with group peers & & 21 & 2.64 & 1.42 \\
\hline
\end{tabular}

$N=200$.

exposure so as to lessen stress of nursing students. Including advance simulators in the nursing education is one of the supportive actions that would decrease students' stress.

The current study showed that the second common source of stress perceived by nursing students is the lack of professional knowledge and skills. This is consistent with the results of other studies [28, 31]. Despite spending three weeks at the nursing laboratories at the college as a method of preparation before going to the hospital students still felt that they still have a lot more to learn while in the college. Thus, they fear making errors while performing nursing procedures in the clinical setting. Furthermore, nursing students in laboratories apply knowledge and skills on manikins designed to meet their educational needs; all this is accomplished without fear of providing harm to a live patient. However, transitioning into the clinical aspect can be very stressful and overwhelming when they deal with live patients.

Among all demographic variables, only "age groups" was found to have a significant effect on students' stress. Post hoc analysis demonstrated that students belonging to the age range 25 years and above claimed to experience less stress than their peers belonging to the other three class groups for the overall stress scale. This can be justified; throughout, all the older students in this study are bridging students and those with years of clinical experience before enrolling in the B.Sc. program tend to experience lower levels of stress than regular students with no previous nursing education or clinical experience. This result is consistent with the study of Bam et al. [32] who found that the older nursing students and those who had been in the nursing program for a period 
TABLE 3: Coping strategies utilized by nursing students.

\begin{tabular}{|c|c|c|c|c|}
\hline Item & Factor ranking & Item ranking & Mean & $\mathrm{SD}$ \\
\hline Avoidance & 4 & - & 1.90 & .92 \\
\hline To avoid difficulties during clinical practice & & 13 & 2.06 & 1.33 \\
\hline To avoid teachers & & 15 & 1.99 & 1.44 \\
\hline To quarrel with others and lose temper & & 17 & 1.86 & 1.42 \\
\hline To expect miracles so one does not have to face difficulties & & 19 & 1.70 & 1.34 \\
\hline To expect others to solve the problem & & 16 & 1.98 & 1.41 \\
\hline To leave it to fate & & 18 & 1.85 & 1.48 \\
\hline Problem solving & 1 & - & 3.35 & .41 \\
\hline To adopt different strategies to solve problems & & 6 & 3.22 & .60 \\
\hline To set up objectives to solve problems & & 1 & 3.43 & .50 \\
\hline To make plans, list priorities, and solve stressful events & & 2 & 3.43 & .54 \\
\hline To find the meaning of stressful incidents & & 5 & 3.32 & .50 \\
\hline To employ past experience to solve problems & & 3 & 3.42 & .51 \\
\hline To have confidence in performing as well as senior schoolmates & & 4 & 3.33 & .49 \\
\hline Staying optimistic & 2 & & 3.01 & .51 \\
\hline To keep an optimistic and positive attitude in dealing with everything in life & & 8 & 3.16 & .52 \\
\hline To see things objectively & & 7 & 3.17 & .89 \\
\hline To have confidence in overcoming difficulties & & 9 & 2.91 & .84 \\
\hline To cry, to feel moody, sad, and helpless & & 10 & 2.81 & .94 \\
\hline Transference & 3 & - & 2.31 & 1.28 \\
\hline To feast and take a long sleep & & 11 & 2.44 & 1.26 \\
\hline To save time for sleep and maintain good health to face stress & & 12 & 2.32 & 1.29 \\
\hline To relax via TV, movies, a shower, or physical exercises & & 14 & 2.04 & 1.36 \\
\hline
\end{tabular}

$N=200$.

of time tended to have a lower level of stress. Also, nursing students are likely to perceive stressful circumstances as less stressful as the nursing education advanced and their average age increased [33]. Nursing students belonging to relatively higher age groups gain knowledge, skills, experience, and self-esteem, which decrease their stress levels in clinical settings [34].

In the current study, problem solving is the most utilized coping strategy by nursing students, and this result is found in other findings of previous studies $[14,16,18]$. However, it does not conform to the findings of Tully [35], who identified avoidance as the most utilized coping strategy. Variations in the year levels of studied nursing students in those studies should be taken into consideration. The predominance of problem-solving strategies in the current study can be justified; throughout, the students in the current study were in their third and fourth years, while the students in Tully's study were in their first and second years of study. The more time the students spent in the clinical settings, the more learning opportunities developed. Hence, the students in Tully's investigation did not have ample learning opportunities to hone problem-solving skills, and, as a result, avoidance was the main coping strategy they employed. Chan et al. [28] showed that nursing students who had previous various clinical learning opportunities were able to hone problem-solving skills in the face of stress related to various situations encountered in clinical training.

\section{Limitations of the Study}

This study delved on the stress perceived by Saudi nursing students in the clinical settings and investigated the presence of possible differences in these perceived stress levels when they were grouped according to their demographic profile. It likewise identified common stressors and coping strategies the student respondents utilized. It did not consider variables such as faculty characteristics and teaching style. A methodological limitation of this study is that the crosssectional design offers information about stress at one point in time, whereas stress level might be varied at a different time. Also, sample was only taken from one college in the University of Hail. It may not represent all nursing students in Saudi Arabia. Therefore, future directions for enhancing the study lean toward utilization of a longitudinal design that will involve student respondents from other colleges of nursing to broaden the generalizability of its findings.

\section{Conclusion and Recommendation}

The current study was consistent with previous investigations conducted on level of stress and coping strategies among nursing students. Assignments and workload and lack of professional knowledge and skills emerged as most reported stressors in this study. On the contrary, stress from teachers and nursing staff is less frequently reported as stressors 
among nursing students. The most common coping strategies used by nursing students in stressful events were problem solving and staying optimistic. Therefore, clinical instructors contribute to the reduction of stress levels experienced by nursing students by encouraging them to utilize problem solving through open communication in order to assist their students in becoming more optimistic. Based on these results, it is required for nursing educators to take actions in order to provide a supportive environment so as to lessen stress of nursing students. Including simulators in the nursing education is one of the supportive actions that would decrease students' stress. Also, clinical instructors need to acknowledge that students are supposed to complete an assignment needed by a due date. Therefore, reducing assignments and the workload for nursing students is essential in order to create a motivating clinical environment. Additionally, understanding and identifying patterns of students' coping strategies is vital in stimulating a supportive learning environment. Clinical educators should build a rapport relationship with their students so as to be able to understand their personalities. As clinical instructors, understanding how their students cope with stress can play a main role in stimulating a supportive healthy environment. Results in this area of research are important in order to help nursing education instructors identify stress-inducing factors in clinical education and thus to highlight the importance of generating suitable solutions.

\section{Conflicts of Interest}

The author declares no conflicts of interest regarding this study.

\section{Acknowledgments}

A sponsorship was granted to this research investigation by the University of Hail (Code 0160639).

\section{References}

[1] M. H. Oermann and K. B. Gaberson, Evaluation and Testing in Nursing Education, Springer Publishing Company, 5th edition, 2016.

[2] K. Blomberg, B. Bisholt, A. Kullén Engström, U. Ohlsson, A. Sundler Johansson, and M. Gustafsson, "Swedish nursing students' experience of stress during clinical practice in relation to clinical setting characteristics and the organisation of the clinical education," Journal of Clinical Nursing, vol. 23, no. 15-16, pp. 2264-2271, 2014.

[3] S. Baraz, R. Memarian, and Z. Vanaki, "Learning challenges of nursing students in clinical environments: a qualitative study in Iran," Journal of Education and Health Promotion, vol. 4, article 52, 2015.

[4] S. Pryjmachuk and D. A. Richards, "Mental health nursing students differ from other nursing students: Some observations from a study on stress and coping: Feature Article," International Journal of Mental Health Nursing, vol. 16, no. 6, pp. 390-402, 2007.

[5] J. Lim, F. Bogossian, and K. Ahern, "Stress and coping in Australian nurses: A systematic review," International Nursing Review, vol. 57, no. 1, pp. 22-31, 2010.
[6] N. A. AlMadani, "Degree education as an entry requirement for qualified nurses in Saudi Arabia: an overview," The Journal of MacroTrends in Health and Medicine, vol. 3, pp. 142-155, 2015.

[7] A. Al Mutair and F. Redwan, "Undergraduate saudi nursing students attitudes towards nursing profession," Journal of Nursing \& Care, vol. 5, no. 329, 2016.

[8] B. M. Mohamed and E. S. Ahmed, "Perception of nursing students towards clinical stressors in the Faculty of Applied Medical Sciences-Al Jouf University-Saudia Arabia," Journal of American Sciences, vol. 8, pp. 608-617, 2012.

[9] S. H. Hamaideh, H. Al-Omari, and H. Al-Modallal, "Nursing students' perceived stress and coping behaviors in clinical training in Saudi Arabia," Journal of Mental Health, pp. 1-7, 2016.

[10] K. Yamashita, M. Saito, and T. Takao, "Stress and coping styles in Japanese nursing students," International Journal of Nursing Practice, vol. 18, no. 5, pp. 489-496, 2012.

[11] A. Chipas, D. Cordrey, D. Floyd, L. Grubbs, S. Miller, and B. Tyre, "Stress: perceptions, manifestations, and coping mechanisms of student registered nurse anesthetists," American Association of Nurse Anesthetists Journal, vol. 80, no. 4, 2012.

[12] M. Liu, K. Gu, T. K. S. Wong, M. Z. Luo, and M. Y. Chan, "Perceived stress among Macao nursing students in the clinical learning environment," International Journal of Nursing Sciences, vol. 2, no. 2, pp. 128-133, 2015.

[13] A. S. Eswi, S. Radi, and H. Youssri, "Stress/stressors as perceived by baccalaureate Saudi nursing students," Middle-East Journal of Scientific Research, vol. 14, no. 2, pp. 193-202, 2013.

[14] A. S. Al-Zayyat and E. Al-Gamal, "Perceived stress and coping strategies among Jordanian nursing students during clinical practice in psychiatric/mental health courses," International Journal of Mental Health Nursing, vol. 23, no. 4, pp. 326-335, 2014.

[15] C. Jimenez, P. M. Navia-Osorio, and C. V. Diaz, "Stress and health in novice and experienced nursing students," Journal of Advanced Nursing, vol. 66, no. 2, pp. 442-455, 2010.

[16] M. Pulido-Martos, J. M. Augusto-Landa, and E. Lopez-Zafra, "Sources of stress in nursing students: a systematic review of quantitative studies," International Nursing Review, vol. 59, no. 1, pp. 15-25, 2012.

[17] L. J. Labrague, "Stress, stressors, and stress responses of student nurses in a government nursing school," Health Science Journal, vol. 7, no. 4, pp. 424-435, 2014.

[18] I. A. Shaban, W. A. Khater, and L. M. Akhu-Zaheya, "Undergraduate nursing students' stress sources and coping behaviours during their initial period of clinical training: A Jordanian perspective," Nurse Education in Practice, vol. 12, no. 4, pp. 204209, 2012.

[19] C. Gibbons, M. Dempster, and M. Moutray, "Stress and eustress in nursing students," Journal of Advanced Nursing, vol. 61, no. 3, pp. 282-290, 2008.

[20] N. Seyedfatemi, M. Tafreshi, and H. Hagani, "Experienced stressors and coping strategies among Iranian nursing students," BMC Nursing, vol. 6, article 11, 2007.

[21] M.-H. Lee, W. L. Holzemer, and J. Faucett, "Psychometric evaluation of the nursing stress scale (NSS) among Chinese nurses in Taiwan," Journal of Nursing Measurement, vol. 15, no. 2, pp. 133-144, 2007.

[22] K. L. Reeve, C. J. Shumaker, E. L. Yearwood, N. A. Crowell, and J. B. Riley, "Perceived stress and social support in undergraduate nursing students' educational experiences," Nurse Education Today, vol. 33, no. 4, pp. 419-424, 2013. 
[23] C. Gibbons, "Stress, coping and burn-out in nursing students," International Journal of Nursing Studies, vol. 47, no. 10, pp. 12991309, 2010.

[24] D. F. Polit and C. T. Beck, Essentials of Nursing Research: Appraising Evidence for Nursing Practice, Lippincott Williams \& Wilkins, Philadelphia, Pa, USA, 8th edition, 2014.

[25] S. Sheu, H. Lin, S. Hwang, P. Yu, W. Hu, and M. Lou, "The development and testing of perceived stress scale of clinical practice," Nursing Research, vol. 5, no. 4, pp. 341-351, 1997.

[26] S. Sheu, H.-S. Lin, and S.-L. Hwang, "Perceived stress and physio-psycho-social status of nursing students during their initial period of clinical practice: the effect of coping behaviors," International Journal of Nursing Studies, vol. 39, no. 2, pp. 165175, 2002.

[27] G. Papazisis, E. Tsiga, N. Papanikolaou, I. Vlasiadis, and D. Sapountzi-Krepia, "Psychological distress, anxiety and depression among nursing students in Greece," International Journal of Caring Sciences, vol. 1, article 42, no. 1, 2008.

[28] C. K. L. Chan, W. K. W. So, and D. Y. T. Fong, "Hong Kong Baccalaureate Nursing Students' Stress and Their Coping Strategies in Clinical Practice," Journal of Professional Nursing, vol. 25, no. 5, pp. 307-313, 2009.

[29] R. Karasek and T. Theorell, Healthy Work: Stress, Productivity, and The Reconstruction of Working Life, The United States of America: Basic books, 1992.

[30] F.-F. Zhao, X.-L. Lei, W. He, Y.-H. Gu, and D.-W. Li, “The study of perceived stress, coping strategy and self-efficacy of Chinese undergraduate nursing students in clinical practice," International Journal of Nursing Practice, vol. 21, no. 4, pp. 401-409, 2015.

[31] N. E. Abdullah I Aedh, "Itedal Abdelraheem Mohamed Ahmed. Factors associated with stress among nursing students (Najran University - Saudi Arabia)," IOSR Journal of Nursing and Health Science, vol. 4, no. 6, pp. 33-38, 2015.

[32] V. Bam, G. Oppong, and M. Ibitoye, "Stress and coping mechanisms of nursing students during clinical practice in Ghana," Journal of Science and Technology, vol. 34, no. 2, pp. 50-59, 2014.

[33] X. Zupiria Gorostidi, X. Huitzi Egilegor, M. Jose Alberdi Erice et al., "Stress sources in nursing practice. Evolution during nursing training," Nurse Education Today, vol. 27, no. 7, pp. 777-787, 2007.

[34] U. Yildiz Findik, A. Ozbas, I. Cavdar, S. Yildizeli Topcu, and E. Onler, "Assessment of nursing students' stress levels and coping strategies in operating room practice," Nurse Education in Practice, vol. 15, no. 3, pp. 192-195, 2015.

[35] A. Tully, "Stress, sources of stress and ways of coping among psychiatric nursing students," Journal of Psychiatric and Mental Health Nursing, vol. 11, no. 1, pp. 43-47, 2004. 


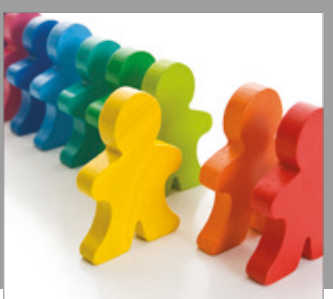

Autism

Research and Treatment
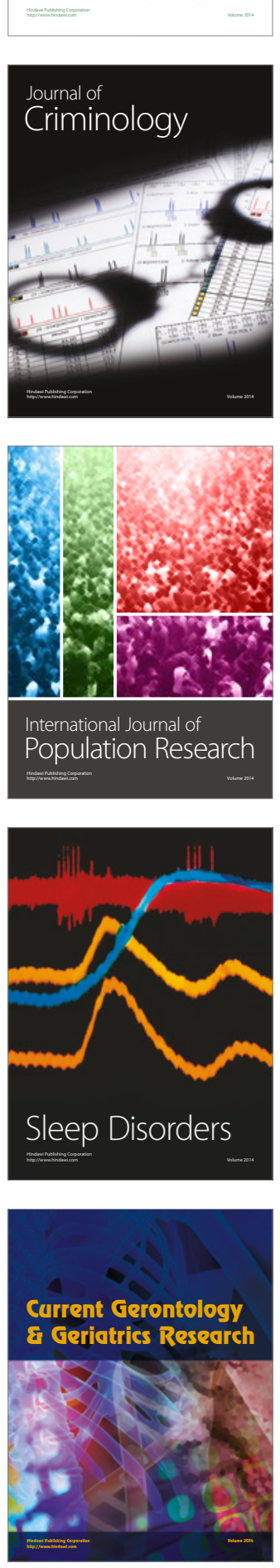

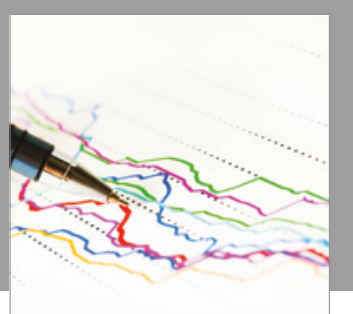

Economics

Research International

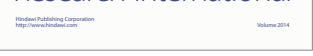

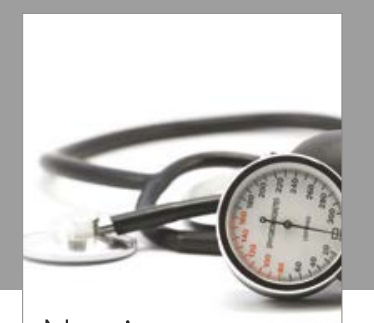

Nursing

Research and Practice

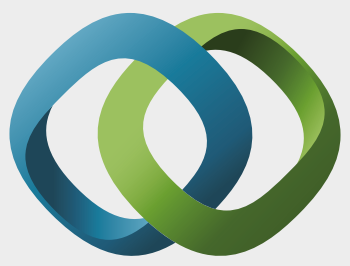

\section{Hindawi}

Submit your manuscripts at

https://www.hindawi.com
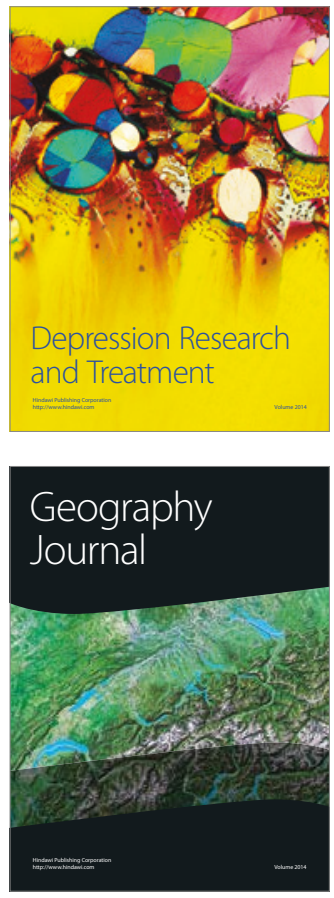
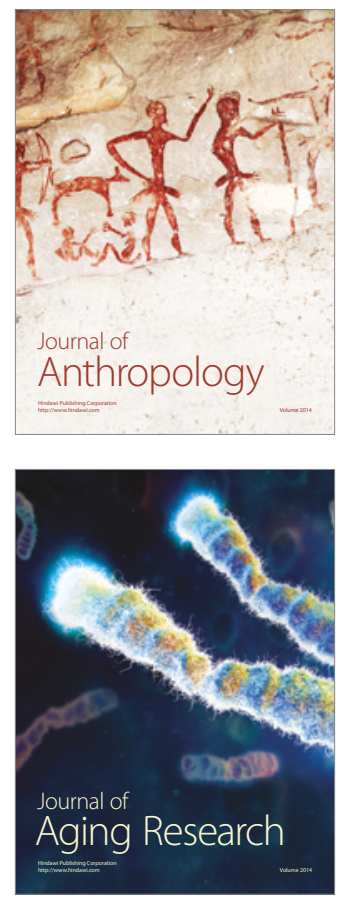
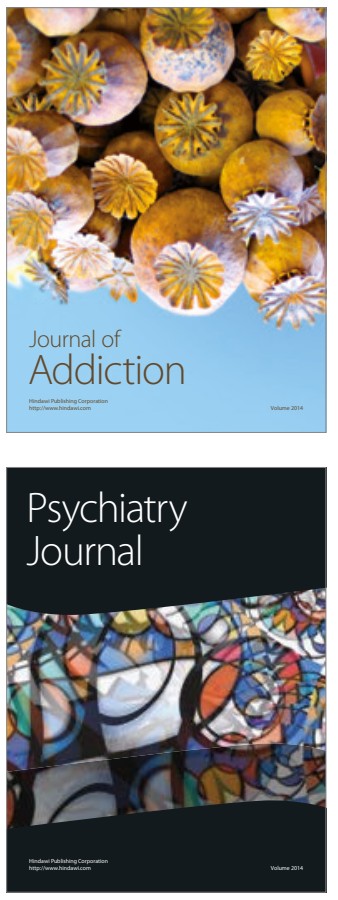

Child Development

Research

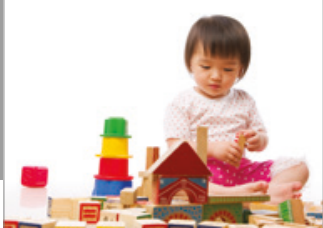

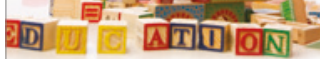
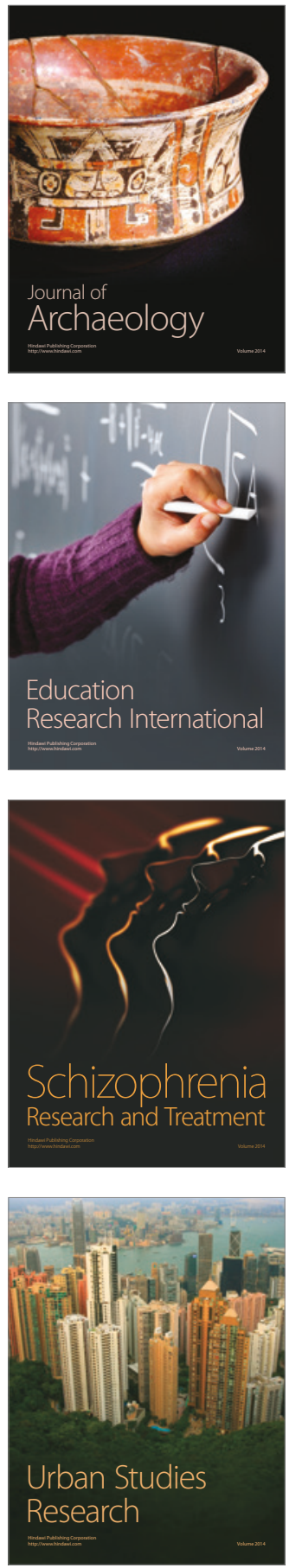